\title{
Dynamic crack mechanism model place in the designing of the buildings
}

\author{
Zoltán Nyikes ${ }^{1, *}$, Tünde Anna Kovács ${ }^{2}$ \\ ${ }^{1}$ Milton Friedman University, 1039 Budapest, Kelta str. 2., Hungary \\ ${ }^{2}$ Óbuda University, Bánki Donát Faculty of Mechanical and Safety Engineering, 1081 Budapest \\ Népszínház str. 8, Hungary
}

\begin{abstract}
The materials that we use always have some defects. Under static, cycling or dynamic load the materials as a function of the crack size and load environment can initiate a fracture. The crack mechanism depends on several factors, like material properties, crack type and the stress kind. The traditional fracture mechanics theories suggest several solutions to predict the crack-grow and the fracture. The fracture mechanism theories are well known in the case of the elastic-plastic behaviour materials and also for the brittle materials under different strain like a high cycle and low cycle fatigue load. These theories are supported by test results. Several researchers evaluated different test methods for determining the fracture toughness on the base of crack-grow behaviour by dynamic tests and determining dynamic fracture toughness. The paper brings the results of the brick blast resistance under the blast load. Damage level was detected as a function of the test setup parameters. The bricks were pre-cracked before the test. The results show that the fracture can be guided by the pre-cracking and decrease the blast affected damage.
\end{abstract}

\section{Introduction}

The material behaviour depends on the strain kind. The material properties are tested traditionally by the static load, like the tensile test, hardness test or bending test. The mechanical properties ductility and toughness also the formability depends on the material testing rate. The simple tensile test result can show different yield strength and tensile strength results in the case of different tensile rates. Materials show more brittle failure mechanisms under a high rated load or shock effect. The high strain rates significantly affect the fracture behaviour of materials.

The fracture mechanics, the testing and modelling of the crack propagation beginning with Griffith's equations [1-5] and research for the determination of the crack propagation. It was followed by the theories of Orowan [2,5,6], Paris [7, 8], Erdogan [7, 9], Tada [8], Irwin [1012], Westergaard [13], Czoboly [14, 15], Gillemot [15, 16], and other important researches. For dynamic loading well known the Charpy impact and drop weight impact tests are. The Charpy impact test method is not suitable to use for the evaluation of dynamic fracture toughness $[17,18]$. The dynamic fracture mechanics theory and evaluation of the fracture

\footnotetext{
* Corresponding author: nyikes.zoltan@uni-milton.hu
} 
toughness test, means the quasistatic fracture theory pioneered by Ireland and Server [19, 20]. The ASTM E24 dynamic fracture toughness testing standard was based on the research work of Ireland and Server.

The fracture mechanics based on the assumption of quasi static conditions are not suitable for understanding the high strain rates affected fracture phenomena. To study this phenomenon it needs to understand the dynamic fracture theory. The dynamic fracture mechanic focuses on two typical problems, one of the cracks under dynamic loading, and another one of the rapid crack propagation. Basically of the theories the K-factors or the energy release rate [21].

The basic law of linear elasticity is Hooke's law (1).

$$
\sigma=\mathrm{E} \varepsilon
$$

Modified by the Lamé constants ( $\lambda$ and $\mu$ ) for isotropic material, the equation can be rewritten as follow (2):

$$
\sigma_{\mathrm{ij}}=\lambda \varepsilon_{\mathrm{kk}} \delta+2 \mu \varepsilon_{\mathrm{ij}}
$$

The modified linear elastodynamic basic elasticity law (2) is the Navier-Lamé equation (3) [21-23]:

$$
(\lambda+\mu) u_{j, j i}+\mu u_{i, j j}=\rho \ddot{u}_{i}
$$

Completed by the scalar and vector potential can earn the Helmholtz wave equation, where $c_{1}$ is the dilational (longitudinal) and $c_{2}$ is the shear waves. In the case of the dynamic fracture beside the dilational and shear waves, it needs to define the Rayleigh waves $c_{R}$ or surface waves also. The defined wave speeds depend only on the material constants.

On the base of the fracture mechanics theories, it can find some experimental method the determine the dynamic stress intensity factor $\left(\mathrm{K}_{\mathrm{Id}}\right)$ and the crack propagation. The research results on the basis of the experimental results determine that the crack propagation depends on temperature, the crack tip and the dynamic fracture toughness which is a material parameter [21].

The dynamic stress intensity factor, on the base of the static stress intensity factor, can be determined by the equation (4) $[17,21]$.

$$
\mathrm{K}_{\mathrm{I}(\mathrm{t})}=\left((3 \cdot \mathrm{S} \sqrt{ } \mathrm{a}) /\left(2 \cdot \mathrm{B} \cdot \mathrm{W}^{2}\right)\right) \cdot \mathrm{Y} \cdot(\mathrm{a} / \mathrm{W}) \cdot \mathrm{k} \cdot \mathrm{u}(\mathrm{t})
$$

Where force $F(t)$ and the displacement $u(t)$ need to be known and k were found by a minimization process. The specimen geometry, three-point bend specimen and the normal force are shown in Figure 1.

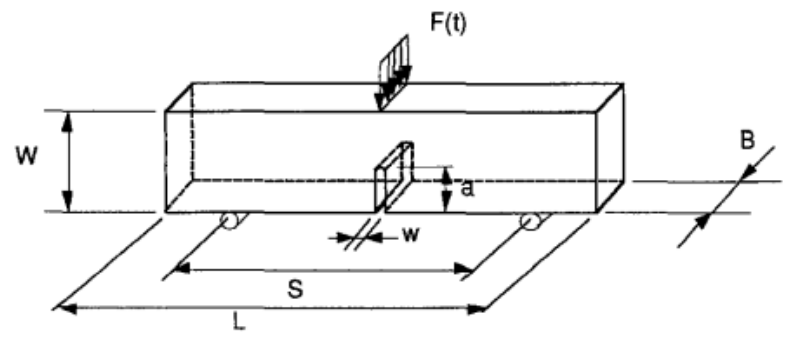

Fig. 1. Three-point bend specimen [21] 
To introduce the calculation of the stress intensity factor and the dynamic load affected crack propagation it needs to distinguish between static and dynamic crack [22, 23]. For dynamic crack, propagation testing understood the traditional Hopkinson bar technique [18, 24-27]. Several theories and test methods based on the Hopkinson bar experimental model to determine the dynamic fracture toughness were done.

\section{Experimental methods and materials}

Several test methods and theories to understand the dynamic load affected crack propagation and the dynamic fracture mechanic $[18,21,24]$ were studied. On the basis of the studied research [28-30] and the available test and explosive material, experimental method and test setup was designed. It was found that the tested samples in the case of the rigid material had pre-crack. The crack propagation was studied as a function of the dynamic load and the precrack size and geometry. For the dynamic tests, explosive material and the load calculated from the explosive mass and TNT equivalent equation (5) [31] was used :

$$
\mathrm{W}_{\mathrm{TNT}}=\left(\Delta \mathrm{H}_{\mathrm{EXP}} / \Delta \mathrm{H}_{\mathrm{TNT}}\right) \mathrm{W}_{\mathrm{EXP}}
$$

where: $\mathrm{W}_{\mathrm{TNT}}(\mathrm{kg})$ is the TNT volume equivalent mass, $\Delta \mathrm{H}_{\mathrm{EXP}}(\mathrm{MJ} / \mathrm{kg})$ is the blasting energy, $\Delta \mathrm{H}_{\mathrm{TNT}}(\mathrm{MJ} / \mathrm{kg})$ is the TNT blast energy and $\mathrm{W}_{\mathrm{EXP}}(\mathrm{kg})$ is the calculated explosive mass.

The blast load can determine by Hopkinson-Cranz law (6) where R (m) the distance of the target from the object, the load of the explosion $\mathrm{Z}\left(\mathrm{mkg}^{-(1 / 3)}\right)$ determined from the $\mathrm{W}(\mathrm{kg})$ explosive mass volume of TNT equivalent by $(6)[31,32,33]$ :

$$
\mathrm{Z}=\mathrm{R} /(\sqrt[3]{ } \mathrm{W})
$$

The Mills equation for nascent gas pressure $\mathrm{P}_{\mathrm{SO}}(\mathrm{kPa})$ determination (7), where $\mathrm{W}$ is the explosive mass in the TNT equivalent $(\mathrm{kg}), \mathrm{R}$ is the explosive distance from the object $(\mathrm{m})$ $[31,32]$ :

$$
\mathrm{P}_{\mathrm{SO}}=\mathrm{R} / \mathrm{Z}^{3}-\mathrm{R} / \mathrm{Z}^{2}+\mathrm{R} / \mathrm{Z}
$$

\subsection{Experimented material}

The used material and test sample was a regular concrete brick (usually used for building constructions with the dimension of $600 \times 200 \times 50 \mathrm{~mm}$ ). The used brick (Ytong) was made from natural raw materials (quartz sand, lime, cement and water). This kind of brick has good fire resistance, thermal insulation, sound insulation, it is lightweight construction material and ecological durable. The test sample (brick) was prepared by pre-cracks as is shown in Figure 2 . 

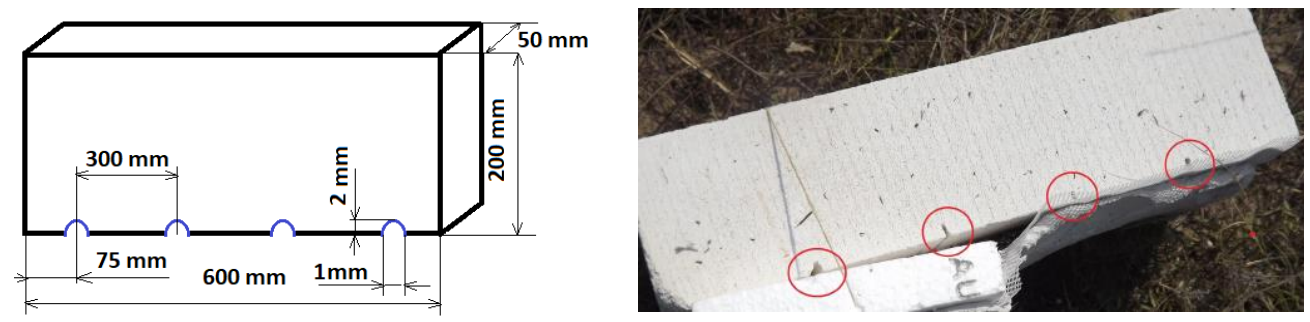

Fig. 2. Test sample

\subsection{Experimental method}

For the tests the prepared bricks (shown in Figure 2.) were used and the used test loads were earned from two kinds of explosive material. The used explosive materials were TNT and SEMTEX. The used quantity in the case of all experiments was $400 \mathrm{~g}$ and the calculated TNT equivalent is shown in Table 1. The experimental ground floor explosion setup is shown in Figure 3.

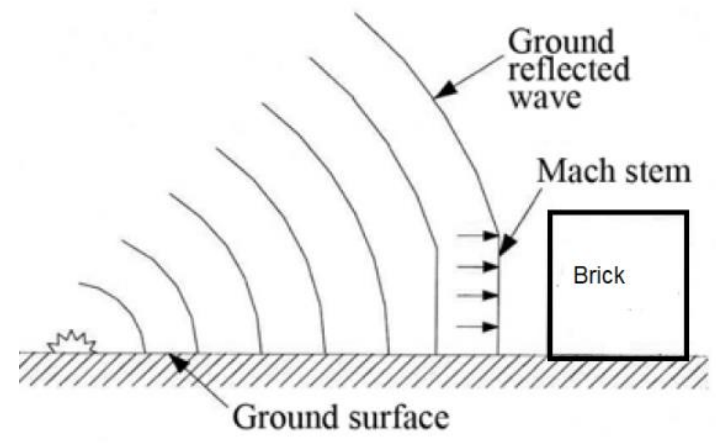

Fig. 3. Ground floor explosion $[31,35]$

The target bricks are also on the ground floor located from the target $1 \mathrm{~m}$. The blast load (6) and the explosion established nascent gas pressure is determined by (7).

Table 1. Calculated load and gas pressure.

\begin{tabular}{|c|c|c|}
\hline $\begin{array}{c}\text { Name of explosive } \\
\text { material }\end{array}$ & Load $\mathbf{Z}\left(\mathbf{m k g}^{-(1 / 3)}\right)$ & $\begin{array}{c}\text { Nascent gas pressure } \\
\text { PSo (kPa) }\end{array}$ \\
\hline TNT & 1.35 & 0.6 \\
\hline SEMTEX & 1.2 & 0.72 \\
\hline
\end{tabular}

The damage affected by the explosion is shown in Figure 4 and Figure 5. It can be seen that the TNT explosion in the case of the same ground setup ( $1 \mathrm{~m}$ distance between the explosion and the test sample) resulted in higher damage than the exploded SEMTEX. 


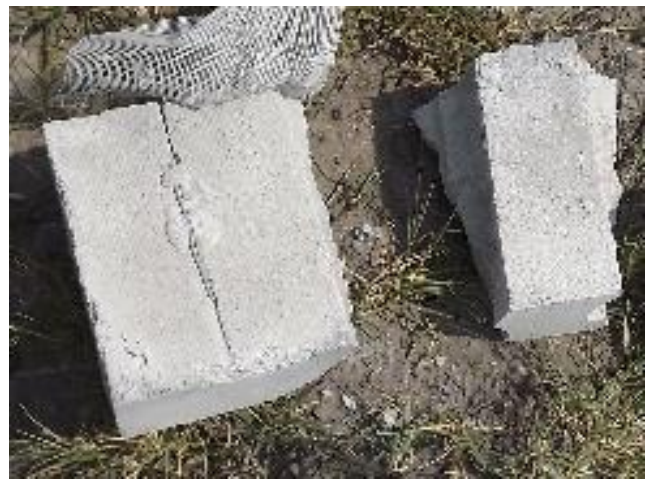

Fig. 4. Exploded by TNT

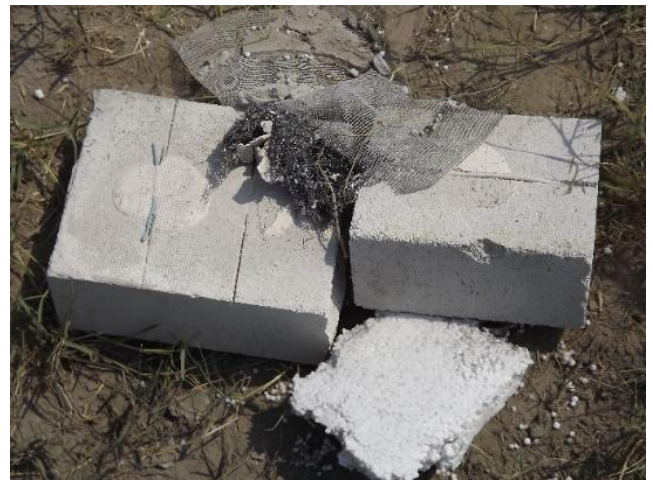

Fig. 5. Exploded by SEMTEX

\section{Results and conclusion}

On the basis of the test results, it can be concluded that the used TNT explosion affected bigger damage than the SEMTEX explosion. It can also be noticed, that the calculated TNT explosion established load was higher than the SEMTEX even though the nascent pressure was reversed. About the damage level, the load value is relevant.

It needs to be concluded that the crack propagation followed the pre-cracks. The bricks did not show breaking in another area. This reason is very important because the damage is governable in the case of the bricks tested by the pre-crack.

The plan is to establish new tests to understand the pre-crack size and geometry effect in the crack propagation. Also, it needs to do some other test methods to compare the results and find a relationship between the material properties and the pre-crack damage effect. On the basis of the test results, it can be suggested for the building designers that in the case of a critical infrastructure building design make allowance for the crack locations.

The presented results are results from the initial experiments of a test series on the base of the dynamic fracture mechanism theories and test models.

\section{References}

1. N. P. Louat, B. B. Rath, Plastic Flow and the Griffith Fracture Criterion, Acta Metallurgica, Vol. 35, No. 12, pp. 2921-2927, 1987, https://doi.org/10.1016/00016160(87)90291-4

2. J. Weertman, Fracture Mechanics: A Unified View For Griffith-Irwin-Orowan Cracks, Acta Metallurgica, Vol. 26, No. 11, 1978, pp. 1731-1738, https://doi.org/10.1016/00016160(78)90084-6

3. K. Huanga, T. Shimadab, N. Ozaki et all, A Unified and Universal Griffith-Based Criterion for Brittle Fracture, International Journal of Solids and Structures, Vol. 128, No. 1, 2017, pp. 67-72, https://doi.org/10.1016/j.ijsolstr.2017.08.018

4. N.P. Andrianopoulos, P.S. Theocaris, The Griffith-Orowan Fracture Theory Revisited: The T-Criterion, International Journal of Mechanical Sciences, Vol. 27, No. 11-12, 1985, pp. 793-801, https://doi.org/10.1016/0020-7403(85)90010-4

5. N.P. Andrianopoulos, P.S. Theocaris, The Griffith-Orowan Fracture Theory Revisited: The T-Criterion, International Journal of Mechanical Sciences, Vol. 27, No. 11-12, 1985, pp.

793-801, https://doi.org/10.1016/0020-7403(85)90010-4 
6. S. N. Bandyopadhyay, Orowan Mechanism for Abrupt Localized Flow And Fracture Initiation in Metals Ahead of a Yielding Notch, Engineering Fracture Mechanics, Vol. 16, No. 6, 1982, pp. 871-887, https://doi.org/10.1016/0013-7944(82)90011-X

7. P. Paris, F. Erdogan, A Critical Analysis of Crack Propagation Laws, J. Basic Eng., Vol. 85, No. 4, 1963, pp. 528-533, https://doi.org/10.1115/1.3656900

8. H. Tada, P.C. Paris, G.R. Irwin, The Stress Analysis of Cracks Handbook, New York, 2000, ISBN-10: 0791801535, DOI: https://doi.org/10.1115/1.801535

9. F. Erdogan, Fracture Mechanics, International Journal of Solid and Structures, 37, 2000., pp. 171-183.

10. G. R. Irwins, Linear Fracture Mechanics, Fracture Transition, and Fracture Control, Engineering Fracture Mechanics, 1968, Vol. I, pp. 241-257., https://doi.org/10.1016/00137944(68)90001-5

11. G.R. Irwin, Analysis of Stresses and Strains Near the End of a Crack Traversing a Plate, Journal of Applied Mechanics, Vol. 24, 1957, pp. 361-364,

12. A.R. Torabi, B. Shahbazian, Notch Tip Plastic Zone Determination by Extending Irwin's Model, Theoretical and Applied Fracture Mechanics, Vol. 108, 2020, https://doi.org/10.1016/j.tafmec.2020.102643

13. H.M. Westergaard, Bearing Pressures and Cracks, Bearing Pressures Through a Slightly Waved Surface or Trough a Nearly Flat Part of a Cylinder, and Related Problems of Cracks, Journal of Applied Mechanics, Vol.6, pp. 49-53.

14. E. Czoboly, B. Csizmazia, I. Havas, Experimental Determination of Plastic Zones, Material Sciences, Vol. 32, No. 1, 1996., pp. 87-98.

15. F. Gillemot, E. Czoboly, I. Havas, Fracture Mechanics Applications of Absorbed Specific Fracture Energy: Notch and Unnotched Specimens, Theoretical and Applied Fracture Mechanics, Vol. 4., 1985, pp. 39-45, https://doi.org/10.1016/0167-8442(85)900412

16. L.F. Gillemot, Criterion of Crack Initiation and Spreading, Engineering Fracture Mechanics, vol. 8, 1976, pp. 239-253., DOI:10.1016/0013-7944(76)90089-8

17. C. Bacon, J. Farm and J.L. Lataillade: Dynamic Fracture Toughness Determined from Load-point Displacement, Experimental Mechanics, 1994. September pp.217-223.

18. Fengchun Jiang, Kenneth S. Vecchio: Hopkinson Bar Loaded Fracture, Experimental Technique: A Critical Review of Dynamic Fracture Toughness Tests Applied Mechanics Reviews NOVEMBER 2009, Vol. 62 / 060802-1 Copyright (C) 2009 by ASME Downloaded 05 Aug 2009 to 137.110.118.115. Redistribution subject to ASME license or copyright; see http://www.asme.org/terms/Terms_Use.cfm

19. Ireland, D. R., 1976, "Critical Review of Instrumented Impact Testing," Dynamic Fracture Toughness International Conference, The Welding Institute of American Society for Metals, London, Effects Technology, Inc., Technical Report No. 79-55.

20. Server, W. L., : "Impact Three-Point Bend Testing for Notched and Precracked Specimens," J. Test. Eval., 6, 1978, pp. 29-34.

21. Dietmar Gross, Thomas Seelig: Fracture Mechanics With an Introduction to Micromechanics Third Edition 2018 Springer pp. 221-237

22. Jianfei Li et al.: A new method for measuring the dynamic fracture toughness under blast loads using an arc-edge rectangle with edge notches, Theoretical and Applied Fracture Mechanics $112 \quad$ (2021) $102891 \quad$ https://doi.org/10.1016/j.tafmec.2020.102891 https://www.sciencedirect.com/science/article/pii/S0167844220304663 
23. A. Mubeen, K. Kim, Cylindrical Specimens for $\mathrm{K}_{1 \mathrm{C}}$ of Rocks, International Journal of Mechanical Sciences, No. 11/12, pp. 711-715, 1985, https://doi.org/10.1016/00207403(85)90003-7, https://www.sciencedirect.com/science/article/abs/pii/0020740385900037

24. Sia Nasser, Jon B. Isaacs, John E. Starrett: Hopkinson Technique for Dynamic Recovery Experiments, Proceedings: Mathematical and Physical Sciences, Vol. 435 . Issue 1894 (Nov. 8, 1991) pp. 371-391.

25. Sia Nemat-Nasser: Variational Methods in the Mechanics of Solids Proceedings of the IUTAM Symposium on Variational Methods in the Mechanics of Solids held at Northwestern University, Evanston, Illinois, U.S.A. 11-13 September 1978 pp.60-66

26. Sia Nemat-Nasser: Mechanics Today, Volume 5 Pergamon mechanics today series 1980 ISBN 0-08-024249-9

27. Mechanical Testing and Evaluation was published in 2000 as Volume 8 of the ASM Handbook. The Volume was prepared under the direction of the ASM Handbook Committee. pp 939-955

28. D. Cormie, G. Mays, S. Smith, Blast Effects on Buildings, Third edition, London, 2020, ISBN 978-0-7277-6147-7

29. H. K. Kutter, C. Fairhurst, On the Fracture Process in Blasting International Journal of Rock Mechanics and Mining Sciences \& Geomechanics Abstracts. Vol. 8, pp. 181-202., 1971., https://doi.org/10.1016/0148-9062(71)90018-0

30. L. Davison, Shock Wave and High-Pressure Phenomena, Berlin Heidelberg, 2008, ISBN 978-3-540-74568-6, DOI 10.1007/978-3-540-74569-3

31. V. Karlos, G. Solomos, "Calculation of Blast Loads for Application to Structural Components," Publication Office of the European Union, 2013

32. L. Figuli, Š. Jangl, D. Papán, "Modelling and Testing of Blast Effect On the Structures," IOP Conf. Series: Earth and Environmental Science 44, 2016.

33. L. Figuli, C. Bedon, Z. Zvaková et al. Procedia Eng. 199, pp. 2463-2469 (2017)

34. Z. Zvakova, L. Figuli, V. Kavicky, et al. Transport Means - Proceedings of the International Conference, pp. 1100-1104 (2016),

35. David Cormie, Geoff Mays, Peter Smith: Blast Effects on Buildings, Third edition, pp. 31-45 ICE Publishing London 2020. ISBN 978-0-7277-6147-7 